\title{
The Cradle, Berthe Morisot
}

\author{
Elinor Kapp
}

This is the second in a short series of articles on portialts of children from the point of viow of a child poychiatist.

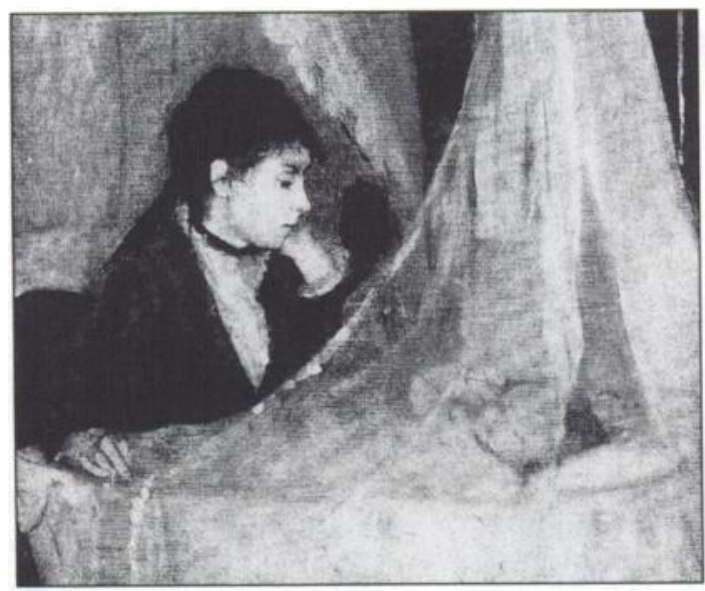

Fig. 1. The Cradle, Berthe Morisot. With kind permission of Musée d'Orsay, Paris.

This reproduction of Berthe Morisot's wellknown painting The Cradle was taken from an advertising campaign under the slogan That vital element of Tranquillity'. To a superficial view this is certainly so. It is an adorable picture, which has been made into a greetings card for new mothers, showing a young woman watching over her sleeping baby. However, study it for a while and you begin to feel that perhaps the real reason it is so loved is that under what might otherwise be a superficial prettiness it tells deep truths about what it is like to be a mother. Only a male advertising executive could pigeon-hole it under 'tranquillity'. Any mother, consciously or not, will resonate to the underlying sleepless anxiety shown in the tense fingers of the right hand and the serious expression. This is not a girl posing prettily with a doll; this is a young woman who has already learnt that babies are liable to wake up, scream, become ill, twist your heart in unexpected ways and show themselves as a new and terrifyingly independent life form. In short, she has already realised that anxiety is the dark thread running through all the joys of motherhood. This young mother resting beside her sleeping baby is, perhaps for the first time, thinking ahead to a future marked by growth and change, pleasure and pain, and knowing she will never again be totally 'free'. She is changed irrevocably; nothing and noone can alter the fact that she is a mother. She stares down on the sleeping face and sees her life, past, present and future mirrored there.

This element of tension adds enormously to the depth and poignancy of the picture. Trying to see how this is achieved I note the basic shape, which is two interlocking and well balanced triangles.

The three main features, mother's face, child's face and her right hand lie in a triangle that draws the eye around each in turn. The light area, formed by the draperies forms a softer, slightly curved triangle with the points outside the picture, and also brings the eye back to the right hand.

The palette is limited. Shades of indigo blue, from dark (almost black) to a slate shade, and cream through to beige with a few carefully placed hints of a soft brownish pink. There may be tiny highlights of pure white on the pillow and the mother's face, but if so they are subordinate to the softer cream highlights on the cradle and its curtains. It is difficult to tell from where the light comes, although it must be in front. Perhaps it is diffused light from a candle, just below chair level and near the artist, increasing the sense of intimacy and participation in the scene.

The formal pattern is disguised by irregular edges and patches of darker colour breaking up the background, balancing the composition to the left and right and throwing the mother and cradle into sharper focus. The mother's pose 'mirrors' the baby's. Her left hand rests 
on her cheek following the baby's bent right arm. This kind of 'mirroring' of posture has been shown by video recordings to be a constant repetitive feature of mother-baby interactions. It is not, as might be thought, the baby imitating the mother; research shows that it is always initiated by the baby and then imitated by the mother. It is as if mothers are saying to these strange beings from outer space. "Look! there is sentient life on earth, it is friendly and you can influence it." Bables deprived of this interaction not only grow up physically and mentally handicapped, they often die.

The initial focal point is the mother's face. She is drawn in clearly and the features emphasised by the darkness of hair and dress, and the warm flesh tints. The open front of the dress and the light line of the wrist lead the eye immediately towards the baby, following her intent gaze. The baby's face forms the secondary focus. Much more lightly drawn, the obscuring transparency of the net curtain provides a convincing artistic reason for this and ensures there is no competition as the eye travels comfortably to and fro between the faces. The soft indistinctness draws us into the pleasure of sleep and gives the observer an instant of repose after the watchfulness of being with the mother. I feel that the subtle tertiary focus is the key to deeper feeling. Look how the eye automatically slides either along the base of the triangle, or down the straight line of the mother's back and arm, or down the curve of the curtain with its pink ribbons. In the lower left corner we rest on the tense right hand a moment. Perhaps the mother has only just pulled that pretty net around, caught in that lovely moment when you think the baby has finally dropped off and can relax almost completely. Almost - but not quite! Never. ever, quite completely relaxed again.

Elinor Kapp, Consultant Psychiatrist, Gwent Community Health NHS Trust, Child and Adolescent Mental Health Service, St Cadoc's Hospital, Lodge Road, Caerleon. Gwent NP6 1XQ

\title{
Writing an introductory handbook for trainees
}

\author{
Richard C. Barnes and Stephen M. Earnshaw
}

\begin{abstract}
'Induction days' are becoming more popular for trainees and are a useful way of communicating important local information to the now intake. The authors feel that a handbook given out during the induction can serve as an aide-memoire, and have provided a suggested layout which they themselves have used in preparing several such books.
\end{abstract}

The first few days in a new job are often difficult for trainees, and even more so if they are 'virgin' psychiatrists. An unfamiliar hospital, which may be large and disorientating, presents an additional challenge to clinical duties, and the experience of change is one most trainees have to face at least twice a year. Induction days are a useful step (Slatford, 1994) but often present a great deal of information in a short time, and focus on general rather than specifically local issues. Providing some form of written information can complement the induction process.

In an increasing number of units, introductory handbooks are becoming popular to provide guidance for those early days. We both have experience in writing such handbooks - and in the reading of other people's. We have found the 